\title{
Game Research on Internet Finance Innovation and Supervision
}

\author{
Qian Wang \\ School of Economics and Management \\ Nanjing University of Science \& Technology \\ Nanjing, China
}

\begin{abstract}
Building a new relationship between financial innovation and supervision is the key to the reform of regulatory system in China. In recent years, financial innovation represented by Internet finance has developed rapidly, but the blank of supervision has made the financial industry "barbaric" growth. Although the central government has introduced a series of policies to strengthen financial supervision, the excessive involvement of the government may hinder financial innovation. Therefore, this paper uses game theory to study how to achieve an effective balance between financial innovation and financial supervision, and finally gives policy recommendations for the institutional choice of financial innovation and regulatory relations.
\end{abstract}

Keywords-Internet financial innovation; game theory; financial supervision; institutional choice

\section{INTRODUCTION}

In recent years, Internet, big data, cloud computing and other information technology tools have been widely used. Internet finance provides a platform for demanders and suppliers of funds; it reduces financial transaction costs and improves financial transaction efficiency; the breadth of the scope and scope of business has increased the possibilities for innovation. However, Internet finance innovation is positive and negative externalities. On the one hand, it realizes the rational allocation of resources with a more open, more direct and inclusive and shared financial model; on the other hand, it also appears that financial innovation is "liberalized" under the "three noes" supervision, leading to capital bubbles and systemic risks. Keep accumulating. Therefore, it is necessary to make structural changes to the financial supervision system. The essence of this change lies in constructing a new relationship between financial innovation and supervision, or a new equilibrium mechanism. This is not only related to the effectiveness of China's financial supervision, but also to the ability of China's financial system. It has important theoretical and practical significance for the healthy and orderly development of China's financial market.

\section{LITERATURE REVIEW}

Western countries first carried out research on financial innovation and supervision theory. In the theoretical research of financial innovation, Sibel (1983) proposed the theory of constraint-induced financial innovation, and believed that financial innovation is the self-defense of microfinance organizations pursuing profit maximization in order to eliminate or mitigate external financial suppression. Financial companies avoid the shackles of internal regulation by conducting various forms of financial innovation, such as trading methods, financial instruments, and new financial products. Hicks and Nihans (1983) believe that financial companies must reduce transaction costs in order to increase their own profits. Transaction costs are one of the important factors in financial innovation. The application of technology such as the Internet will help reduce transaction costs and improve efficiency. Hollander (1975) classifies financial innovations, one is to evade regulatory evasion innovation, and the other is a priori innovation that is not related to regulation. On the basis of escaping innovation research, Kane (1981) proposed and described the dialectical relationship between financial innovation and financial supervision based on the research of the US and UK banking markets.

In terms of domestic research on financial innovation and supervision, some scholars use game theory to analyze. Li Cheng (2009) takes the US subprime mortgage crisis as the starting point and uses game theory to analyze the defects of China's financial supervision. Supervised and coordinated game equilibrium; Wu Jiayu (2011) introduced the Nash equilibrium of pure strategy and hybrid strategy, and analyzed the necessity of strengthening financial supervision; Shuai Qinghong (2014) used game theory to analyze the relationship between regulated and regulated enterprises in the P2P industry. The interaction relationship looks for the balance between the two; Zhong Xiaoying (2016) analyzes the moral hazard and adverse selection problems in the current Internet finance lending market in China, and uses the game theory method of signal transmission and repeated game to analyze the different parameter changes. The influence of game equilibrium indicates that information sharing in the market should be improved. Therefore, this paper will also talk about the relationship between Internet financial innovation and regulatory system from the perspective of game theory, and how to "moderately" regulate. 


\section{THE GAME RESEARCH ON THE RELATIONSHIP} BETWEEN FINANCIAL INNOVATION AND SUPERVISION

From the perspective of materialist dialectics, financial innovation and supervision are a contradiction of opposites and unification. The dynamic game of mutual promotion and mutual restrainment promotes the development of financial markets.

\section{A. Relationship Analysis Based on Complete Information Dynamic Game}

1) Game model premise assumption: The main players are financial supervision enterprises and financial enterprises. It is assumed that there is no monopoly and rent-seeking behavior in financial supervision enterprises. The purpose is to safeguard the public interest, reduce the risk of financial innovation, and bring expected benefits to the society. In the game, the choice of the supervisor's strategy is to maintain supervision or strengthen supervision. The strategic choice of financial enterprises is not to innovate or strengthen innovation. Financial innovation and supervision is a process of seeking balance in the dynamic, and the information sharing between the two is transparent and high in understanding. Therefore, a dynamic game model based on complete information for financial innovation and supervision can be constructed.

2) Parameter setting: When a financial enterprise fails to innovate, its return is $\mathrm{F}$; the excess return after innovation is F1. The loss caused by the increase in risk caused by innovation is $\mathrm{M}$, and the loss M1 caused by innovation leads to the strengthening of supervision. The relevant expected values are $\mathrm{E}(\mathrm{F}), \mathrm{E}(\mathrm{F} 1), \mathrm{E}(\mathrm{M}), \mathrm{E}(\mathrm{M} 1)$; the social benefits brought about by the supervision of the regulatory enterprise are $\mathrm{L}$, and at the same time, The cost of the aspect such as regulatory technology, regulatory innovation, legislation, is $\mathrm{C}$, so the relevant expected values are $\mathrm{E}(\mathrm{L})$ and $\mathrm{E}(\mathrm{C})$.

\section{3) Strategy selection}

- Assuming that the financial enterprise does not innovate and the supervisory entity does not supervise and maintain supervision, the entire income pattern will not change. Therefore, the expected return of the supervisory entity and the financial enterprise in this state is $[\mathrm{E}(\mathrm{F}), \mathrm{E}(\mathrm{L})]$.

- Assume that when the enterprise innovates, the regulatory enterprise chooses not to supervise and maintain supervision. When maintaining the status quo of supervision, financial enterprises can obtain excess expected return E (F1) because of innovation, but the risk arising from lack of supervision will cause financial enterprises to lose $\mathrm{E}(\mathrm{M})$ to society, so the expected return of both parties is $[\mathrm{E}(\mathrm{F})+\mathrm{E}(\mathrm{F} 1)$, $\mathrm{E}(\mathrm{L})-\mathrm{E}(\mathrm{M})]$

- It is assumed that the regulatory enterprises have increased supervision during the innovation of enterprises. Financial enterprises will suffer the loss E (M1) caused by supervision while obtaining the expected excess returns, and financial supervision enterprises will evade innovation. On the basis of risk due to the increase of supervision, the corresponding regulatory cost $\mathrm{E}(\mathrm{C})$ has been paid. The expected return of both parties is $[\mathrm{E}(\mathrm{F})+\mathrm{E}(\mathrm{F} 1)-\mathrm{E}(\mathrm{M} 1), \mathrm{E}(\mathrm{L})-\mathrm{E}$ (C)].

- It is assumed that financial enterprises do not innovate, but regulated enterprises have strengthened supervision, which will not have too much impact on corporate income, but will increase supervision costs, society expects revenue to decline, and social expected returns are expressed as $[\mathrm{E}(\mathrm{F}), \mathrm{E}(\mathrm{L})-\mathrm{E}(\mathrm{C})]$.

TABLE I. FINANCIAL INNOVATION AND REGULATORY EXPECTATIONS RETURN MATRIX

\begin{tabular}{|l|l|l|l|}
\hline & & \multicolumn{2}{|c|}{ Internet finance company } \\
\hline & & not innovation & \multicolumn{2}{|c|}{ innovation } \\
\hline \multirow{5}{*}{$\begin{array}{l}\text { Supervisory } \\
\text { authority }\end{array}$} & $\begin{array}{l}\text { maintenance or non- } \\
\text { regulation }\end{array}$ & $\mathrm{E}(\mathrm{F}), \mathrm{E}(\mathrm{L})$ & $\begin{array}{l}\mathrm{E}(\mathrm{F})+\mathrm{E}(\mathrm{F} 1), \mathrm{E}(\mathrm{L})- \\
\mathrm{E}(\mathrm{M})\end{array}$ \\
\cline { 2 - 4 } & $\begin{array}{l}\text { Strengthen } \\
\text { supervision }\end{array}$ & $\begin{array}{l}\mathrm{E}(\mathrm{F}), \mathrm{E}(\mathrm{L})- \\
\mathrm{E}(\mathrm{C})\end{array}$ & $\begin{array}{l}\mathrm{E} \quad(\mathrm{F})+\mathrm{E}(\mathrm{F} 1), \mathrm{E}(\mathrm{L})-\mathrm{E}(\mathrm{C}) \\
(\mathrm{E})\end{array}$ \\
\hline
\end{tabular}

4) Analysis of game results: As can be seen from "Table I", when financial companies do not innovate, the expected returns of the regulators are $\mathrm{E}(\mathrm{L})$ and $\mathrm{E}(\mathrm{L})-\mathrm{E}(\mathrm{C})$. I $\mathrm{E}(\mathrm{L})>\mathrm{E}(\mathrm{L})-\mathrm{E}(\mathrm{C})$, he optimal strategy of the regulatory enterprise is not regulated, and the game equilibrium of financial innovation and supervision is $[\mathrm{E}(\mathrm{F}), \mathrm{E}(\mathrm{L})]$, ie (not Innovation, maintenance or non-regulation). When financial companies innovate, the regulatory expected returns corresponding to the supervisory entities are $\mathrm{E}(\mathrm{L})-\mathrm{E}(\mathrm{M})$ and $\mathrm{E}(\mathrm{L})-\mathrm{E}(\mathrm{C})$, respectively. Therefore, the height between $\mathrm{E}(\mathrm{M})$ and $\mathrm{E}(\mathrm{C})$ determines the choice of the optimal strategy. If the loss caused by innovation is less than the cost of supervision, the behavioral concept of financial supervision should be weakened, the space for innovation and risk of Internet financial innovation should be given, and the strategy of maintaining the status quo of supervision should be chosen (innovation, maintenance or non-regulation); When the expected loss caused by the risk exceeds the regulatory cost, it is selected (innovation, strengthen supervision).

When the regulator chooses to maintain or not to supervise, natural innovation can bring additional benefits, choices (innovation, maintenance or non-regulation). When the supervisory authority chooses to strengthen supervision, the enterprise innovation expectation income is $\mathrm{E}(\mathrm{F})+\mathrm{E}(\mathrm{F} 1)-$ $\mathrm{E}(\mathrm{M} 1)$. At this time, it is necessary to compare the excess return $\mathrm{E}(\mathrm{F} 1)$ of innovation with the loss $\mathrm{E}$ (M1) caused by 
regulation: when $\mathrm{E}(\mathrm{F} 1)>\mathrm{E}(\mathrm{M} 1)$, it indicates that the financial enterprise's final expected return from innovation exceeds its response. Loss of cost, in order to obtain excess profits in the market will continue to innovate, while the regulatory companies will continue to strengthen supervision to mitigate the losses caused by risks, at this time (innovation, strengthen supervision) strategy has formed a noncooperative game equilibrium State, the so-called Nash equilibrium; if $\mathrm{E}(\mathrm{F} 1)<\mathrm{E}(\mathrm{M} 1)$, the expected return after the enterprise deducts the loss is smaller than the expected return when it is not innovative. At this time, the Internet financial enterprise prefers not to carry out financial innovation. Regulatory companies will also save on regulatory costs because companies abandon innovation, and weaken supervision, so that they will return to the above-mentioned first game equilibrium state (no innovation, maintenance or non-regulation). In this state, the behavior of the supervisory body will not only dampen the motivation of Internet finance companies for innovation, but also the financial risks caused by the inaction of supervision. Therefore, the supervisory body should adopt appropriate and effective supervision to achieve (innovation, strengthen supervision) such a game equilibrium and optimal strategy, not only promote Internet financial innovation, but also effectively prevent and supervise the generated financial risks and problems.
In summary, in the case of complete information, both financial companies and regulators will consider innovation and regulation through changes in cost and benefits. Since the static, complete information market is a hypothesis, it is necessary to elicit analysis in a dynamic, incomplete information market.

\section{B. Analysis of the Relationship Between Dynamic Games Based on Incomplete Information}

1) Game model premise assumption: Assuming that both the company and the regulator are "rational people", they will make optimal decisions on the benefits. The former is the maximization of its own utility, while the latter is financial stability. In this dynamic game process, there is a choice of succession. It is also assumed that the enterprise makes decisions first, and the regulators change their strategic choices according to their innovative decisions. Compared with the former, the biggest difference of the model is that we assume that the game subject cannot fully grasp opponent's information and knowledge, which means that there is information uncertainty in the game between the two parties. Since it is assumed that Internet finance companies make decisions first, the basic path and process of financial innovation and regulation are shown in "Fig. 1".

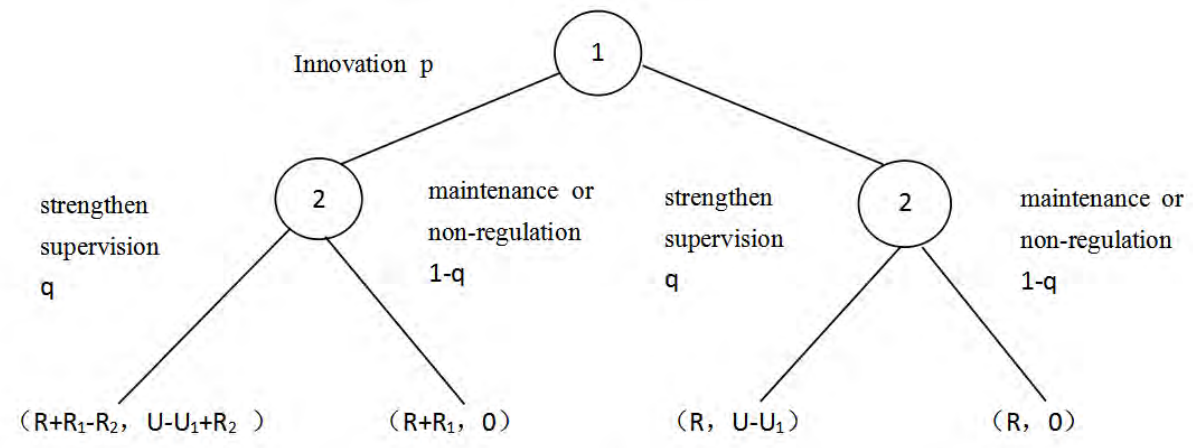

Fig. 1. The basic path and process of the game between financial innovation and supervision.

2) Parameter setting: Innovating is $1-\mathrm{p}$; the noninnovative utility is $\mathrm{R}$, the excess utility of innovation is $\mathrm{R} 1$, the loss utility caused by innovation leads to R2, and the expected utility of financial enterprise is $E(f)$. Set the supervisory authority to strengthen the supervision probability to $\mathrm{q}$, the probability of not supervising or maintaining the status of supervision is 1-q; the social utility $\mathrm{U}$ brought by supervision, and the cost increase due to strengthening supervision, the utility loss in this respect is $\mathrm{U} 1$, the supervisory body The expected utility is $\mathrm{E}(\mathrm{g})$.

3) Strategy selection: Assume that financial enterprises do not innovate, and that the regulatory bodies do not supervise and maintain supervision. Financial enterprises will not change. It is still not innovative and effective. R. Non-regulatory maintenance supervision will not bring social effects to the regulatory bodies, so financial enterprises and the income function of the supervisory subject is $[R, 0]$.
- Assuming that when the enterprise innovates, the regulatory enterprise chooses to maintain or not to supervise. At this time, the financial enterprise can obtain the excess return $\mathrm{R}_{1}$ because of innovation, and the non-regulatory maintenance supervision will not bring social utility to the regulatory body, so the income of the financial enterprise and the regulatory entity The function is $\left[R+R_{1}, 0\right]$.

- It is assumed that the regulatory enterprises have increased supervision during the enterprise innovation. While the financial enterprises obtain the excess return $R_{1}$, the loss utility caused by the regulatory constraints will be $R_{2}$, and the regulatory body will increase its supervision. The social utility $U$ brought, and the cost increased due to the strengthening of supervision. The utility loss in this respect is $U_{1}$, so the income function of financial enterprises and regulatory entities is $\left[R+R_{1}-R_{2}, U-U_{1}+R_{2}\right]$. 
- It is assumed that financial enterprises are not innovative, but regulated enterprises have strengthened supervision, which will not have too much impact on corporate income, but the regulatory body will increase supervision costs, and society expects revenue to fall by $\mathrm{U}_{1}$, so financial enterprises and regulatory entities The income function is [R, U$\mathrm{U}_{1}$.

4) Analysis of game results: Finally, from the game tree in "Fig. 2", we can know the utility value under different strategies, and we can get the expected utility of financial enterprises and regulatory entities. The extreme value can then be derived for the expected utility with respect to the first-order partial derivative of q.

$$
\begin{aligned}
& E(f)=\mathrm{p}\left[\mathrm{q}\left(R+R_{1}-R_{2}\right)+(1-\mathrm{q})\left(R+R_{1}\right)\right]+(1-\mathrm{p})[q R+(1-q) R]=p\left(R+R_{1}-\mathrm{q} R_{2}\right)+(1-\mathrm{p}) R \\
& E(g)=q\left[p\left(U-U_{1}+R_{2}\right)+(1-\mathrm{p})\left(U-U_{1}\right)\right]+(1-q)[p * 0+(1-p) * 0]=q\left(p R_{2}+U-U_{1}\right)
\end{aligned}
$$

Calculate the expected utility of the two, then through the first-order partial derivative, the probability of enterprise innovation under the incomplete information, and the probability of financial supervision enterprises strengthening supervision.

The above shows that the choice of financial enterprise innovation and supervision subject supervision strategy will change according to the changes in the utility of the other party, and the two will influence each other. Further analysis of $\mathrm{p}$ and q: Generally speaking, the use of legal and other regulatory means to supervise the innovation of financial enterprises is relatively static and static, so the changes of $U$ and $R_{2}$ are relatively small. The excess utility $R_{1}$ of enterprise innovation will also increase, because on the basis of the relatively fixed $\mathrm{R}_{2}$, the regulatory probability will increase and the supervision will gradually increase. When the supervisory body begins to strengthen supervision, the utility $\mathrm{U}_{1}$ lost by the supervision cost will increase, but when the supervision is carried out for a period of time, the relevant technology and the supervision system are continuously improved, which will cause $U_{1}$ to decline compared with the initial period of supervision, so the supervisory body Will continue to choose to maintain this regulation. Financial enterprises have acquired financial risks because of innovations, and financial institutions have begun to strengthen supervision. Under such ever-increasing supervision, enterprises will choose to give up innovation and financial suppression. Using $\mathrm{p}$ and $\mathrm{q}$ to describe, that is, the probability of enterprise innovation rises first and then declines, and the regulatory probability increases. At this time, two-game equilibrium between (innovation and strengthening supervision) and (no innovation and strengthening supervision) are formed.

In summary, the construction of a new relationship between Internet finance innovation and regulation is an institutional arrangement of private rights and public power, and is an institutional choice.

\section{Relationship Analysis Based on Evolutionary Game Model}

1) Game model premise assumption: Enterprises and regulatory entities are "rational people" and pursue their own interests. The model assumes that the biggest difference compared to the previous one is that we assume that the supervisory body is regulated by means of spot checks, and the supervisory body's strategy includes verification or nonverification, and the choice is based on uncertain probability. Internet finance companies choose to follow or evade regulation, and also choose according to uncertain probability. Both sides of the game do not know opponent's strategic choices in advance, but they all understand the income of both parties in the game. At the same time, it is assumed that as long as the supervisors choose to check, they can find out whether Internet finance companies are evading supervision, and Internet finance companies know this.

2) Parameter setting: The supervision cost of the supervisory entity is c. The financial enterprise follows the cost of supervision and $c_{1}$, and evades the cost $c_{2}$ undertaken by the supervision. Financial enterprises follow the supervision, the social income of financial enterprises is $u_{1}$, and the social benefits of the supervision entities are $u_{2}$ Financial enterprises evade supervision, the financial income of financial enterprises is $\mathrm{u}_{3}$, and the additional income is $\mathrm{d}$. Regulatory subject social benefits $\mathrm{u}_{4}$. Once the regulated company has verified that there is evasion of supervision, it will accept F's fine. Assuming that $\mathrm{x}$ is the probability that the supervisory authority chooses to check, the probability of non-verification is $1-\mathrm{x}$; the probability that Internet finance companies choose to follow regulation is $y$ and the probability of evading supervision is $1-\mathrm{y}$.

3) Strategy selection

- Assuming that the supervisory body chooses not to verify, the financial enterprise chooses to evade supervision. The regulatory body does not verify that it will not incur any costs, but can obtain the social benefits of $u_{4}$. In the case of financial enterprises choosing to evade supervision, the additional income is $\mathrm{d}$, the cost of evading supervision payments is $c_{2}$, and the social benefits of evading supervision are $\mathrm{u}_{3}$. Therefore, the income function of the supervisory entity and the financial enterprise is $\left[\mathrm{u}_{4}, \mathrm{~d}+\mathrm{u}_{3}-\mathrm{c}_{2}\right]$.

- Assuming that the regulatory body chooses to verify, the financial enterprise chooses to follow the regulation. In the case where the regulatory body chooses to verify, it needs to pay the regulatory cost c, and at the same time it will receive social benefits $u_{2}$. In the case of financial enterprises following the supervision, it is the social benefit $\mathrm{u}_{1}$ that can be obtained in accordance with the cost $\mathrm{c}_{1}$ undertaken by the supervision. Therefore, the income function of the regulatory body and the financial enterprise is $\left[\mathrm{u}_{2}-\mathrm{c}\right.$, $\left.\mathrm{u}_{1}-\mathrm{c}_{1}\right]$.

- Assuming that the regulatory body chooses to verify, the financial enterprise chooses to evade supervision. 
In the case of the supervisory body choosing to verify, the cost of supervision c, which is assumed, can also obtain social benefits $\mathrm{u}_{4}$. In the case that the financial enterprise chooses to evade supervision, it will obtain the social benefit $\mathrm{u}_{3}$ in order to avoid the cost $\mathrm{c}_{2}$ of supervision. Once the regulated enterprise has found out that there is evasion of supervision, it will accept the penalty of $\mathrm{F}$. Therefore, the income function of the supervisory entity and the financial enterprise is $\left[\mathrm{F}-\mathrm{c}+\mathrm{u}_{4}, \mathrm{~d}+\mathrm{u}_{3}-\mathrm{c}_{2}-\mathrm{F}\right]$.

- Assuming that the supervisory body chooses not to verify, the financial enterprise chooses to follow the supervision. In the case that the supervisory body chooses not to verify, the cost it bears is zero, and at the same time, the social benefit $\mathrm{u}_{2}$ can be obtained. In the case that financial enterprises choose to follow the supervision, the cost they have to bear is $\mathrm{c}_{1}$, and the social benefit $\mathrm{u}_{1}$ can be obtained. Therefore, the income function of the supervisory entity and the financial enterprise is $\left[\mathrm{u}_{2}, \mathrm{u}_{1}-\mathrm{c}_{1}\right]$.

TABLE II. REGULATORY VERIFICATION SELECTION AND REGULATORY RESULTS TO SELECT THE EXPECTED RETURN MATRIX

\begin{tabular}{|l|l|l|l|}
\hline & & \multicolumn{2}{|c|}{ Internet finance company } \\
\hline & $\begin{array}{l}\text { follow the } \\
\text { regulation }\end{array}$ & $\begin{array}{l}\text { evade } \\
\text { supervision }\end{array}$ \\
\hline \multirow{2}{*}{$\begin{array}{l}\text { Supervisory } \\
\text { authority }\end{array}$} & verify & $\mathrm{u} 2-\mathrm{c}, \mathrm{u} 1-\mathrm{c} 1$ & $\begin{array}{l}\mathrm{F}-\mathrm{c}+\mathrm{u} 4, \mathrm{~d}+\mathrm{u} 3- \\
\mathrm{c} 2-\mathrm{F}\end{array}$ \\
\cline { 2 - 4 } & $\begin{array}{l}\text { not } \\
\text { verify }\end{array}$ & $\mathrm{u} 2, \mathrm{u} 1-\mathrm{c} 1$ & $\mathrm{u} 4, \mathrm{~d}+\mathrm{u} 3-\mathrm{c} 2$ \\
\hline
\end{tabular}

4) Analysis of game results: According to the solution method of the replicon dynamic equation, the regenerative dynamic equation of the supervisory authority can be obtained as follows:

$F(x)=d x / d t=x(1-x)\left[y\left(u_{2}-c-u_{2}\right)+(1-y)\left(F-\mathrm{c}+u_{4}-u_{4}\right)\right]=x(1-x)[F-\mathrm{c}-y F]$

In the same way, it can be concluded that the replicon dynamic equation of the Internet financial institution is:

$F(\mathrm{y})=d y / d t=y(1-y)\left[x\left(u_{1}-c_{1}-d-u_{3}+c_{2}+F\right)+(1-\mathrm{x})\left(u_{1}-c_{1}-d-u_{3}+c_{2}\right)\right]$

By combining the two equations, the supervisory authority and the Internet financial institution can be combined into a system with five dynamic equilibrium points, $0(0,0), \quad \mathrm{A}(1,0), \mathrm{B}(0,1) . \quad), \quad \mathrm{C}(1,1)$ and $\mathrm{G}\left(\frac{\mathrm{u}_{1}-c_{1}-d-u_{3}+c_{2}}{-F}, \frac{F-c}{F}\right)$. According to the local stability of the Jacobian matrix, the corresponding phase diagram can be drawn by using the symbol of the matrix determinant at the equilibrium point and the sign of the trace.

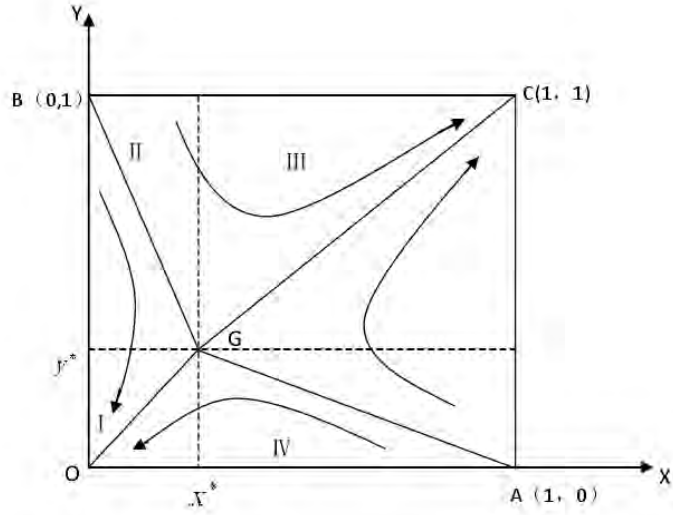

Fig. 2. Evolutionary game dynamic process phase diagram.

From the above "Fig. 2", the whole area is divided into four parts. When it is in area I, the model will converge to $(0,0)$, the equilibrium strategy is (not verified, evade supervision); when located in area III, the model will converge to $(1,1))$, the equilibrium strategy is (verification, follow supervision); when located in area II, BG divides the area into two parts. If it is located in $\mathrm{y}^{*} \mathrm{BG}$, the model will converge to the point $(\mathrm{x}=0, \mathrm{y}=0)$, and the equilibrium strategy is (Do not check, evade supervision), if it is located elsewhere in Area II, the model will converge to the point $(x=1, y=1)$, the equilibrium strategy is (check, follow supervision); when located in Area IV, the model is also divided In both cases, if within $\mathrm{X}^{*} \mathrm{AG}$, the model will converge to the point $(x=0, y=0)$, the equilibrium strategy is (no verification, evasion supervision), otherwise the model will converge to the point $(\mathrm{x}=1, \mathrm{y}=1)$, the equilibrium strategy is (check, follow regulation). Therefore, the stable equilibrium points of the game are $(x=0, y=0)$ and $(x=1, y=1)$, and the equilibrium strategies are (no verification, evasion of supervision) and (check, follow supervision). From the graph, it is obvious that the model converges to the probability of the point $(x=1, y=1)$, that is, the equilibrium strategy is (check, follow the supervision) as the area of the quadrilateral $\mathrm{AGBC}$, and the area of the other quadrilateral AGBO is the equilibrium strategy. (Do not check, evade supervision). In the real life, for the steady development of the Internet financial industry, our best state is definitely (checking, following supervision). We think that the area of the quadrilateral AGBC can be larger, that is, the quadrilateral AGBO has a smaller area. To facilitate the calculation, we derive the quadrilateral AGB0 area as:

$$
S_{A G B O}=\frac{1}{2}\left(\mathrm{x}^{*}+\mathrm{y}^{*}\right)=\frac{1}{2}\left(\frac{-u_{1}+c_{1}+d+u_{3}-c_{2}+F-\mathrm{c}}{F}\right)
$$

It can be concluded from the above formula that in order to make the area of the quadrilateral AGBO smaller, the values of $u_{1}, c 2, c$, and $F$ are larger, and the values of $c 1, d$, and $\mathrm{u} 3$ are smaller.

For supervisory authorities, their strategic choices are mainly affected by the cost of verification payments and the amount of fines paid by Internet finance companies when they are checked out to evade supervision, and there is no correlation between the social benefits that the regulatory 
authorities choose to verify or not to verify. This also shows that although the regulators have an obligation to protect the public interest from infringement, because the size of social welfare has no direct impact on its regulatory strategy, and the regulatory authorities may have the intention to promote innovation in the financial sector, directly causing the laissez-faire of the regulatory authorities. This has intensified the risks in the Internet finance field.

For Internet finance companies, their strategic choices are subject to the social benefits they receive from evading supervision and the costs they pay, the social benefits they receive from supervision and the costs they pay, the extra benefits from evading supervision, and the impact of the amount of fines suffered. As Internet finance companies follow the social benefits of regulation, the cost of evading supervision, and the increase in the amount of fines that may be faced after evading supervision, the probability of choosing to follow regulation will increase. As Internet financial institutions follow the costs of supervision, the social benefits of evading supervision, and the increase in additional income, the probability of choosing to evade supervision will increase. The fundamental goal of Internet finance companies is to maximize their own interests. Therefore, the size of the income is the main factor affecting their strategic choices. Whether it is to comply with regulation or to evade supervision, as long as the income is large enough, Internet financial institutions have incentives to evade supervision and choose to evade supervision.

In summary, in real life, in the game between the supervisory authority and the Internet financial enterprise, it is important to explore the appropriate income cost penalty system for the development of the regulatory system.

\section{THE INSTITUTIONAL CHOICE OF FINANCIAL INNOVATION AND REGULATORY RELATIONSHIP}

\section{A. Value Judgment}

From the perspective of game and equilibrium, the value orientation of traditional financial supervision in China focuses on the "dual values" of efficiency and security, but in fact it is a "balance on the wire", thus falling into the "executive-led, profit-oriented, regulatory center". Therefore, nowadays we need to establish a "three-dimensional value" of financial fairness, security and efficiency. Financial fairness can connect security and efficiency and become a balance point between security and efficiency. Encourage people to break the "prisoner's dilemma", from noncooperation to cooperation, and promote the development of inclusive finance.

First, due to information asymmetry, financial enterprises need to act as intermediaries. Unlike traditional finance, the Internet has increased the diversity of financial model innovation. On the other hand, innovation should create conditions for eliminating information asymmetry, but also because of information. The asymmetry has led to the profitoriented opportunistic behavior of financial enterprises, and the development trend of financial innovation "derealization" has brought about new information asymmetry.
The failure of the government and the market illustrates the problem of the regulatory regulatory paradigm, which is the game between the regulatory authorities and Internet finance companies.

Second, the reform of the financial regulatory system and the establishment of a process of mutual competition and rational allocation between private rights and public power can also be said to be a game of "financial innovation" and "financial suppression." Financial innovation is an impulse instinct to promote social development driven by private rights. Financial suppression is the conscious involvement of government public power in financial markets. Excessive intervention will restrict financial deepening. Through this kind of conflict and game, it is a full consideration of the degree of development of financial "liberalization".

Third, the game of financial innovation and regulation is also a game of positive and negative externalities of financial activities. The scarcity of financial resources brings positive externalities to financial activities. In the legal life, people consciously and unconsciously carry out cost-benefit accounting in all aspects of the legal operation, always try to fight for more rights and try to get rid of legal obligations, "struggle for rights" reflects the positive and negative external Sexual game.

\section{B. Policy Recommendations}

First, regulation requires strict market access. All financial business must be included in the supervision, and all financial operations must be licensed. The key is to clarify the basic attributes, classification and identification criteria of various financial behaviors, clarify the responsible departments of various financial behaviors and regulatory responsibilities so that each type of financial innovation can be applied to the corresponding attribute classifications. We can find the corresponding regulatory destination, which is the behavioral supervision system we need to build.

Second, the supervision needs to grasp the tightness, that is, the appropriateness of supervision. The first thing to do is to have a law to follow. For each type of financial activity, there should be a corresponding regulatory system to regulate and delimit. This requires the regulatory authorities to speed up the innovation of the regulatory system, timely fill in the shortcomings of the system, shorten the time lag of the introduction of regulatory policies, and keep pace with the innovation of financial institutions. Second, we must grasp the degree and boundary of supervision and insist on doing something different. Excessive supervision and inadequate supervision are undoubtedly not conducive to the improvement of regulatory efficiency. In the context of increasingly clear accountability for regulatory duties, special attention needs to be paid to over-regulation.

Third, regulators need to pay attention to the direction of financial innovation in a timely manner. Financial innovation is essentially an internal driving behavior of financial institutions to evade or get rid of their internal and external constraints. Financial innovation is more in the sense of evading existing regulatory regulations or exploring the blank areas of supervision. From the perspective of 
maintaining regulatory regulation, regulators should pay close attention to their trends in financial innovation, follow up on their pace in a timely manner, and should not forget their own positioning and lead financial innovation to healthy waterways.

\section{CONCLUSION}

If Internet finance innovation is the soul of financial development, then regulation is the ambassador of innovation. Without innovative finances, the unsupervised innovations are easy to escape. Supervision and innovation are both antagonistic and unified, and should reach a state of equilibrium to promote the development of finance. If the supervisor is driven by interests, it always tries to circumvent the current regulatory regulations, obtain advanced income through financial service models and product innovation, and achieve regulatory arbitrage; at this time, regulators should follow up and monitor the financial innovations that occur in time. Its compliance and risk, timely targeted regulatory measures, to fill gaps and loopholes in regulatory regulations.

\section{ACKNOWLEDGMENT}

This research was supported by the teachers of Nanjing University of Science and Technology.

\section{REFERENCES}

[1] Silber W L. The process of financial innovation. American Economic Review, 1983,73 pp.89-95.

[2] Niehans J. Financial innovation, multinational banking, and monetary policy. Journal of Banking\&Finance, 1983, 7 (4) pp.537-551.

[3] Holland R C. Bank holding companies and financial stability. Journal of Financial and Quantitative Analysis, 1975, 10 (4) pp.577-587.

[4] Kane EJ. Accelerating inflation, techno logical innovation and the decreasing effectiveness of banking regulation. Journal of Finance, 1981, 36 (2) pp.355-367.

[5] Li Cheng, Ma Guoxiao, Li Jia. Interpretation of China's Financial Supervision Coordination Mechanism Based on Evolutionary Game Theory. Financial Research, 2009 (5) pp.186-193.

[6] Wu Jiawei. Analysis of the Necessity of Strengthening Financial Supervision from the Perspective of Game Theory. Corporate Herald, 2011 (19) pp.34-35.

[7] Shuai Qinghong. Game Analysis of P2P Network Lending Supervision. Journal of Sichuan University (Philosophy and Social Sciences), 2014 (4) pp.133-138.

[8] Zhong Xiaoying. Research on Adverse Selection and Moral Hazard in Internet Consumer Finance - Based on the Perspective of Signal Transmission and Repeated Game. Financial Theory and Practice, 2016 (12) pp.59-63.

[9] Xie Ping, Zou Chuanwei, Liu Hai. The Necessity and Core Principles of Internet Financial Supervision. International Finance Research, 2014(8).

[10] Yan Linwei. Analysis of the problems and countermeasures of China's financial supervision China's collective economy, 2018 (7) 